\title{
Active Biopolymer Coating Based on Sodium Caseinate: Physical Characterization and Antioxidant Activity
}

\author{
Marika Valentino ${ }^{1}$, Stefania Volpe ${ }^{2, *}$, Fabio Angelo Di Giuseppe ${ }^{1}\left(\mathbb{D}\right.$, Silvana Cavella $^{1}$ \\ and Elena Torrieri ${ }^{1}(D)$ \\ 1 Department of Agricultural Science, Via Università 133, 80055 Portici (NA), Italy; \\ marika.valentino@unina.it (M.V.); fabioangelo.digiuseppe@unina.it (F.A.D.G.); cavella@unina.it (S.C.); \\ elena.torrieri@unina.it (E.T.) \\ 2 Centre of Food innovation and Development in the Food Industry, Via Università 100, \\ 80055 Portici (NA), Italy \\ * Correspondence: stefania.volpe2@unina.it; Tel.: +39-08-12539328
}

Received: 4 June 2020; Accepted: 19 July 2020; Published: 22 July 2020

\begin{abstract}
The objective of this work was to investigate the effect of sodium caseinate concentration on physical-chemical properties of coating solutions and films obtained by casting as a starting point for the development of an active coating for minimally processed fruits or vegetables. Sodium caseinate solutions at different concentrations $(4 \%, 8 \%, 10 \%, 12 \%, 14 \%)$ were used as a coating system. The coating viscosity and desorption kinetic were characterized. Minimally processed fennels were coated by dipping and the liquid and dry coating thickness were estimated by assessing the amount of coating on fennel during draining as a function of solution properties (concentration and viscosity). Film obtained by casting were also characterized in terms of equilibrium moisture content, color, and water vapor permeability. The potential of using the sodium caseinate solution to obtain active coating was investigated by adding gallic acid or rosemary oil to sodium caseinate solution at $4 \%$. The antioxidant capacity of the coating was evaluated by DPPH test. Results show that sodium caseinate solutions follow a Newtonian behavior in the range of concentration investigated and the viscosity increased as solids concentration increased, following a power law. The drying rate was in the range $0.0063-0.00107 \mathrm{mg}_{\mathrm{H}_{2} \mathrm{O}} \cdot \mathrm{mg}_{\text {solids }}{ }^{-1} \cdot \mathrm{min}^{-1} \cdot \mathrm{m}^{-2}$ as a function of sodium caseinate concentration. The average liquid and dry coating thickness on fennels were in the range 20-70 and 0.7-6.4 $\mu \mathrm{m}$, respectively. The water vapor permeability slightly decreased as the solid concentration increased. Active coating showed good antioxidant properties.
\end{abstract}

Keywords: viscosity; desorption kinetic; coating thickness; gallic acid; rosemary oil; water vapor permeability

\section{Introduction}

Edible coatings are a promising preservation technology that allow to extend the shelf life of food products, slowing down their quality decay through the reduction of mass transfer of gas, moisture or aromas. In addition, coatings can be used as carrier of active/functional additives that can contribute to the shelf life extension and/or improve food nutritional quality [1]. Protein-based coatings have shown promising results in extending the shelf life of fresh-cut fruits and vegetables related to their excellent gas barrier characteristics and good mechanical properties. The coatings' ability to modify the atmospheres surrounding fruits and vegetables allow to slow down their respiration rate, extending the shelf life [2]. Among naturally occurring proteins, casein and its derivatives have been extensively studied due to their availability, low cost, and complete biodegradability. Sodium caseinate (SC) is 
obtained by acid precipitation of casein and can be considered an interesting biomaterial for food packaging, due to its excellent thermoplastic and film-forming properties [3]. The high degree of inter/intra molecular interactions make the casein film stiff and brittle; thus, a plasticizer, such as glycerol, polyethylene glycol (PEG) or sorbitol, is required [4].

Sodium caseinate coatings were able to prevent weight loss of Bing cherries after 60 days of storage at $4{ }^{\circ} \mathrm{C}[5]$ but did not preserve the polyphenols of berry cactus fruit. A previous study reported that $2 \%$ sodium caseinate coating reduced the weight and ascorbic acid loss of apricot after 42 days of storage at $4-6{ }^{\circ} \mathrm{C}[6]$. The coating performance is affected by the coating thickness on the food product [7] which, in turn, depends on the composition and viscosity of the solution/dispersion used to make the coating [8].

Aiming to prolong shelf life, maintain food quality, and reduce the use of synthetic preservative (i.e., citric acid, benzoic acid, sorbic acid, propyl gallate, sodium nitrite) [9], many studies have been focused on active packaging, obtained by adding natural substances such as polyphenols, to extend the shelf life of food [10].

Gallic acid (2,3,4-trihydroxybenzoic acid) is a natural phenolic compound present in many plants, either as a free acid or as a component of tannins, that acts as strong free radical scavenger and is commonly used to prevent lipid oxidation in processed food [11]. The content of gallic acid in food matrix ranges from 103 to $105 \mu \mathrm{g} / \mathrm{g}$ for oregano and sage herbs, from 783.5 to $2375.7 \mathrm{mg} / 100 \mathrm{~g}$ of dry weight for clove, and from 276 to $907 \mathrm{mg} / 100 \mathrm{~g}$ of fresh weight for Portuguese chestnut [12-14].

Rosemary essential oil (REO) is known for its strong antioxidant properties and several studies have demonstrated the effectiveness of REO for controlling the oxidation of food products [15-17]. The $\mathrm{IC}_{50}$ of REO extracted from different rosmarin plants was found to be in the range of 16.45 to $23.80 \mathrm{mg} / \mathrm{mL}$ [18] and from 33 to $164 \mu \mathrm{g} / \mathrm{mL}$ [19].

Although extensive research has been done in the area of edible films and coatings for fresh and minimally processed fruits and vegetables, many of the results of the scientific literature are not easily applicable to cases and conditions other than those investigated due to its empirical nature.

The objective of this work is to investigate the effect of sodium caseinate concentration on some physical-chemical properties of coating solutions and films obtained by casting as a starting point for the development of an active coating for minimally processed fruits or vegetables. Minimally processed fennels were considered as a study case to evaluate the effect of composition and viscosity of sodium caseinate solutions on coating thickness on fennel, after the dipping phases. The antioxidant properties of active sodium caseinate coating, added with gallic acid or rosemary oil, were also evaluated.

\section{Materials and Methods}

\subsection{Materials}

Sodium caseinate from bovine milk, glycerol and chloridric acid $(\mathrm{HCl})$ were purchased from Sigma-Aldrich (Milan, Italy). Fennel heads (Foeniculum vulgare Mill. subsp. vulgare var. azoricum $\mathrm{cv}$ Augusto and Tiziano) were cultivated in Puglia and Calabria and supplied by Commerciale Export Company (Pagani, Italy). Fennel heads were stored at $4{ }^{\circ} \mathrm{C}$ in a refrigerated chamber for $24 \mathrm{~h}$ before testing.

\subsection{Coating/Film-Making Procedure}

The composition of solutions for the coating or film preparation is reported in Table 1. 
Table 1. Composition of coating/film (sodium caseinate (SC), glycerol (Gly), gallic acid (GA), rosemary essential oil (REO)) and activation energy $(E)$, and the pre-exponential factor of Arrhenius-type equation $\left(\eta_{0}\right)$. n.a. = not available data

\begin{tabular}{ccccccc}
\hline Code Sample & $\begin{array}{c}\text { SC } \\
\text { g/100 } \mathbf{~ m L}\end{array}$ & $\begin{array}{c}\text { Gly } \\
\text { g/100 } \mathbf{~ m L}\end{array}$ & $\begin{array}{c}\text { GA } \\
\text { g/100 } \mathbf{~ m L}\end{array}$ & $\begin{array}{c}\text { REO } \\
\mathbf{m L} / \mathbf{1 0 0} \mathbf{~ m L}\end{array}$ & $\begin{array}{c}E \\
\mathbf{~ k J \cdot m o l} \mathbf{- 1}\end{array}$ & $\begin{array}{c}\eta_{\mathbf{0}} \\
\mathbf{P a} \cdot \mathbf{s}\end{array}$ \\
\hline SC + GA & 4 & 0.4 & 0.005 & - & n.a. & n.a. \\
SC + REO & 4 & 0.4 & - & 1.5 & n.a. & n.a. \\
SC 4\% & 4 & 0.4 & - & - & 20.06 & 13.9 \\
SC 8\% & 8 & 0.8 & - & - & 30.23 & 16.6 \\
SC 10\% & 10 & 1.0 & - & - & 31.11 & 16.3 \\
SC 12\% & 12 & 1.2 & - & - & 37.21 & 17.7 \\
SC 14\% & 14 & 1.4 & - & - & 46.45 & 20.3 \\
\hline
\end{tabular}

Sodium caseinate (SC) solutions with protein concentrations at $4 \%, 8 \%, 10 \%, 12 \%$, and $14 \%$ $\left(\mathrm{g} \cdot \mathrm{mL}^{-1}\right.$ ) were obtained by dispersing SC powder in deionized water and stirring continuously for $4 \mathrm{~h}$ at room temperature. Glycerol (Gly) was added as plasticizer to obtain a Gly/SC weight ratio of 0.1.

Only for SC solution at $4 \%$, gallic acid or rosemary essential oil were added to obtain active coating. To prepare the active coating, a $4 \%$ SC solution was prepared by dissolving the SC powder in an $\mathrm{HCl}$ tris buffer at $\mathrm{pH} 8$ by magnetic stirrer for $4 \mathrm{~h}$ at room temperature, then $10 \%$ of glycerol, referred to solid, was added. Then, $0.005 \mathrm{~g}$ of gallic acid (GA) powder was dissolved into $1 \mathrm{~mL}$ of HCI tris buffer using a shaking stirrer (IKA ${ }^{\mathrm{TM}}$ MS 3 Digital Vortex, -Werke GmbH \& Co. KG, Staufen, Germany). Then, the GA solution was added to SC solution $(100 \mathrm{~mL})$ and homogenized under stirring and light protection, to obtain the solution at $50 \mu \mathrm{g} \cdot \mathrm{mL}^{-1}$ of GA.

A mixture of rosemary essential oil (REO) and Tween 80 (4:1) was added to the SC solution, to obtain a final concentration of $1.5 \%(v / v)$ of REO. The solution was homogenized at 15,500 rpm for $4 \mathrm{~min}$ at room temperature by using a rotor-stator homogenizer (UltraturraxR, T 18 IKA, Milan, Italy).

For the films preparation, $5 \mathrm{~mL}$ of solutions were poured into Petri dishes (surface of $56.7 \mathrm{~cm}^{2}$ ) and dried at $30{ }^{\circ} \mathrm{C}$ and $50 \%$ relative humidity $(R H)$, overnight in circulating air system chamber (MMM Medcenter Einrichtungen GmbH, Munich, Germany).

\subsection{Rheological Analysis}

The solution flow curves were acquired as reported in a previous study (see [20]) with small modifications. A stress-controlled rheometer (HAAKE MARS 40 Rheometer, Thermo Fisher Scientific, Waltham, MA, USA) equipped with coaxial cylinders (30 mm outer diameter and $26 \mathrm{~mm}$ internal diameter) has been used. Steady shear tests were carried out at $15^{\circ} \mathrm{C}$ by increasing the shear rate from 1 to $100 \mathrm{~s}^{-1}$.

To study how the temperature affects the viscosity of solutions, viscosity ramp temperature tests were also carried out, from 15 to $81{ }^{\circ} \mathrm{C}$ at $7.5^{\circ} \mathrm{C} / \mathrm{min}$, at constant shear rate of $10 \mathrm{~s}^{-1}$.

An Arrhenius-type equation was applied to describe the effect of temperature on the solution viscosity, as reported by [21]:

$$
\eta=\eta_{0} \exp \left(\frac{E}{\mathrm{RT}}\right)
$$

where $\eta$ represents the apparent viscosity, $\eta_{0}$ the pre-exponential factor, $E\left(\mathrm{~kJ} \cdot \mathrm{mol}^{-1}\right)$ the activation energy, $\mathrm{R}\left(\mathrm{J} \cdot \mathrm{mol}^{-1} \cdot \mathrm{K}^{-1}\right)$ the universal gas constant, and $T(\mathrm{~K})$ the absolute temperature.

The dependence of solution viscosity on SC concentration, calculated at $15,22.5$, and $30^{\circ} \mathrm{C}$, can be described by an empirical power law equation:

$$
\eta=a c^{b}
$$

where $c$ is the SC concentration $(w / w \%)$ and $a(\mathrm{mPa} \cdot \mathrm{s})$ and $b$ are empirical parameters related to the molecular weight of protein. 


\subsection{Kinetics of Water Desorption}

To investigate the effect of the SC concentration on water loss rate and residual water content at the thermo-hygrometric conditions of the casting or drying operation, the kinetics of desorption of SC solution at $4 \%, 8 \%, 10 \%, 12 \%$, and $14 \%(w / v)$ were determined by using a microbalance system (DVS Q5000SA, TA Instrument, New Castle, DE, USA). An amount from 42 to $69 \mathrm{mg}$ of each solution was poured into an aluminum cup and kept at $30{ }^{\circ} \mathrm{C}$ and $50 \%$ of $R H$ until equilibrium (change of weight $<0.001 \%$ for $10 \mathrm{~min})$. Residual water content $(m)\left(\mathrm{g}_{\mathrm{H}_{2} \mathrm{O}} / \mathrm{g}_{\text {tot }}\right)$ was expressed as equilibrium moisture content at $50 \%$ of $R H$.

\subsection{Coating Application on Fennel and Thickness Estimation}

Fennel head (about $500 \mathrm{~g}$ ) was washed under tap water and dried with tissue. Subsequently, the butt end was cut with a sharp knife. Thus, each bulb fennel was dipped by hand into the SC solutions $(4 \%, 8 \%, 10 \%, 12 \%$, and $14 \%(w / v))$ for $2 \mathrm{~min}$ and then quickly withdrawn and drained on metallic grids over the glass vessel containing the solution. The glass vessel was on the top of a balance accurate to $0.01 \mathrm{~g}$ (Mark Ben 3000, Monza, Italia) allowing recording of the SC solution weight over time. The amount of coating on the fennel at any time was calculated as the difference between the initial weight of the SC solution in the glass vessel and the weight recorded at the respective draining time.

The thickness of liquid coatings has been estimated as function of sodium caseinate solutions viscosity and draining time, following the modeling approach for flat plate dip-coating in low capillary number Newtonian liquids as reported by Cisneros-Zevallos and Krochta [8]. Assuming a spherical geometry for the fennel and considering that surface tension force is overshadowed by the viscous and gravity forces, the average liquid coating thickness $\left(h_{\text {avg }}\right)$ can be estimated as:

$$
h_{\text {avg }}=\frac{q}{A}=K\left(\frac{\eta \pi r}{\rho g t}\right)^{1 / 2}
$$

where $q$ was the coating volume $\left(\mathrm{cm}^{3}\right), A$ is the surface area of the fennel $\left(\mathrm{cm}^{2}\right), r$ is the fennel radius $(5 \mathrm{~cm}), \eta$ is the viscosity, $\rho$ is the solution density, $g$ is the gravitational acceleration, $t$ is the draining time, and $K$ is the dimensionless flow factor that can be experimentally determined by linear regression of Equation (3). The coating volume $(q)$ was calculated as coating weight deposited on fennel $(W, \mathrm{~g})$ divided by the coating density $\left(\rho, \mathrm{g} \mathrm{cm}^{-3}\right)$.

At a given draining time, the dry film thickness on fennel surface $\left(H_{\mathrm{avg}}, \mu \mathrm{m}\right)$ was estimated as the function of dry coating load $\left(D_{\mathrm{c}}, \mathrm{g} \cdot \mathrm{cm}^{-2}\right)$ that in turn depends on liquid coating thickness [8]

$$
\begin{gathered}
H_{\mathrm{avg}}=\frac{D_{c}}{\rho_{\mathrm{f}}} \cdot 10 \\
D_{c}=\rho c h_{\text {avg }} 1000
\end{gathered}
$$

where $\rho$ is the coating solution density $\left(\mathrm{g} \cdot \mathrm{cm}^{-3}\right), c$ is the concentration of solids in solution $\left(\mathrm{g} \cdot \mathrm{g}^{-1}\right)$, and $\rho_{\mathrm{f}}$ is the dry film density $\left(\mathrm{g} \cdot \mathrm{cm}^{-3}\right)[8]$.

\subsection{Film Physiochemical Properties}

The solid surface density $\left(\rho_{\mathrm{s}}\right)$ was calculated as:

$$
\rho_{\mathrm{s}}=\frac{C \cdot V}{A}
$$

where $C$ is the solution concentration $\left(\mathrm{mg} \cdot \mathrm{mL}^{-1}\right), V$ is the solution volume poured into the petri dish $(\mathrm{mL})$, and $A$ is the surface area of the petri dish $\left(\mathrm{cm}^{2}\right)$. 
The film density $\left(\rho_{\mathrm{f}}\right)$ was calculated as:

$$
\rho_{\mathrm{f}}=\frac{w_{f}}{A \cdot x}
$$

were $w_{f}$ is the weight of the film $(\mathrm{g}), A$ is the film surface area $\left(\mathrm{m}^{2}\right)$, and $x$ is the film thickness $(\mathrm{m})$.

The color of the film was measured using a colorimeter (Minolta Chroma Meter, CR 300, Osaka, Japan), at least in five areas randomly chosen. Color was reported as Hunter parameters $L^{*}$ (from $0=$ black to $100=$ white), $a^{*}\left(-a^{*}=\right.$ greenness to $+a^{*}=$ redness $)$, and $b^{*}\left(-b^{*}=\right.$ blueness to $+b^{*}=$ yellowness).

The total color difference $(\Delta E)$ was also calculated as follows:

$$
\Delta E=\sqrt{\Delta L^{2}+\Delta a^{2}+\Delta b^{2}}
$$

where $\Delta L, \Delta a^{*}$, and $\Delta b^{*}$ are the differences between the samples and reference color parameters $(L=96.94, a=+0.23, b=+1.85)$.

Film thickness was measured using a micrometer model H062 with sensitivity of $\pm 2 \mu \mathrm{m}$ (Metrocontrol Srl, Casoria, Italy). Five measurements were performed for each sample.

The water vapor permeability (WVP) of the films was evaluated using a gravimetric test according to Volpe and colleagues [20] by means of Payne permeability cup (Carlo Erba, Milan, Italy), as reported by the ASTM [22]. The water vapor permeability (WVP) was calculated at $20^{\circ} \mathrm{C}$ and at $85 \%$ of $R H$, as:

$$
W V P=\frac{d m}{d t} \frac{x}{S \cdot \Delta p}
$$

where $d m / d t$ is the slope of the uptake vapor water curve in the steady state zone, $x$ is the film thickness, $S$ is the area of film mass-transfer surface $\left(9.89 \mathrm{~cm}^{2}\right)$, and $\Delta p$ is the vapor water pressure difference across film. The results are reported as the average of three replications of each sample.

\subsection{Antioxidant Capacity of Bioactive Coating}

The DPPH method was used to determine the free radical scavenging capacity of gallic acid, rosemary essential oil, and their respective bioactive coating. For gallic acid and rosemary essential oil samples, four different dilutions of analyzed samples in ethanol (96\%) were prepared. Then, $2.4 \mathrm{~mL}$ of $30 \mathrm{ppm}$ ethanolic solution of DPPH were mixed with $1 \mathrm{~mL}$ of sample's dilution. All samples were analyzed after $15 \mathrm{~min}$ using a spectrophotometer at $517 \mathrm{~nm}$ against ethanol as reference. The results were expressed as inhibition concentration $\left(\mathrm{IC}_{50}\right)$ in $\mu \mathrm{g} \cdot \mathrm{mL}^{-1}$ [23].

For the bioactive coating, the methods of Hromis et al. [24], with a little modification were used. Briefly, $2.4 \mathrm{~mL}$ of $30 \mathrm{ppm}$ ethanolic solution of DPPH were mixed with $100 \mathrm{mg}$ of bioactive coating. Samples were stored for 2.5 and $4 \mathrm{~h}$ at room temperature in the dark. Then, the samples were centrifugated for $5 \mathrm{~min}$ at 10,000 rpm and filtered by using a $20 \mu \mathrm{m}$ Whatman filter.

For all samples, the absorbance was measured at $517 \mathrm{~nm}$ using a UV-Vis spectrophotometer (V-550 Jasco Inc., Tokyo, Japan) and pure ethanol as reference. The results were expressed as percentage of DPPH free radical activity:

$$
I \%=\frac{A b s_{\mathcal{c}}-A b s_{s}}{A b s_{c}} \cdot 100
$$

where $A b s_{c}$ is the absorbance of the control and $A b s_{s}$ is the absorbance of the sample.

The assay was carried out in triplicate.

\section{Results}

\subsection{Rheological Analysis}

The flow behavior of SC solutions is illustrated in Figure 1A. 

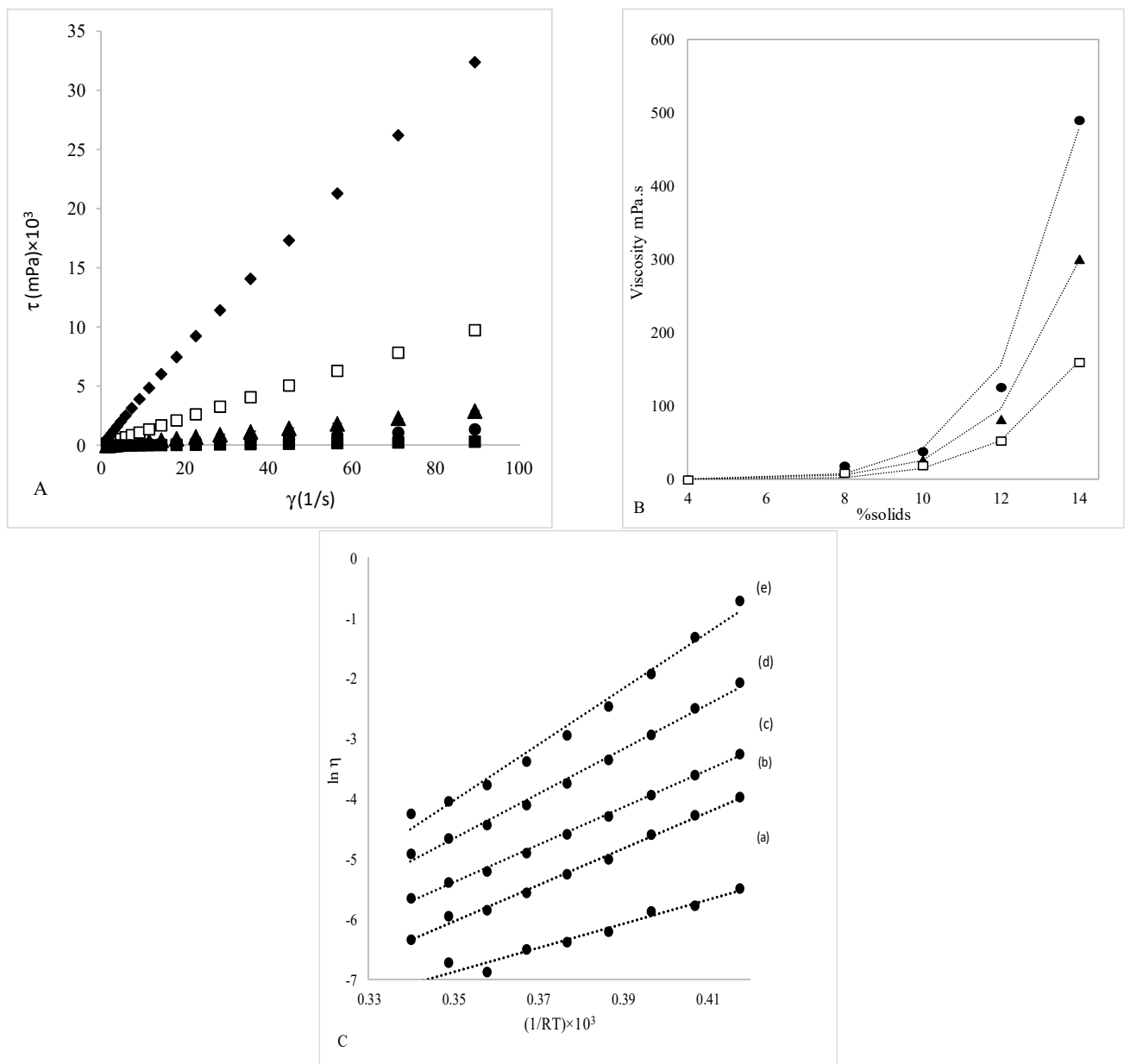

Figure 1. Shear stress versus shear rate of the SC solutions at different concentrations: $4 \%(\boldsymbol{\bullet}), 8 \%(\bullet)$, $10 \%(\mathbf{\Lambda}), 12 \%(\square)$, and $14 \%(\downarrow)(\mathbf{A})$. Effect of solid concentrations on viscosity at three temperatures: $15^{\circ} \mathrm{C}(\bullet), 22.5^{\circ} \mathrm{C}(\boldsymbol{\Delta})$, and $30^{\circ} \mathrm{C}(\square)$. Dot lines represent the predicted value from Equation (2) (B). Effect of temperature (Arrhenius plot) on the viscosity of SC solutions at concentrations of (a) $4 \%$, (b) $8 \%$, (c) $10 \%$, (d) $12 \%$, and (e) $14 \%$ (C).

By increasing the shear rate, all samples presented a linear increase in shear stress; therefore, the SC solutions behaved as a Newtonian fluid in the investigated SC concentration range. The solutions viscosity is strongly affected by the SC concentration, changing from 4 to $14 \%$. The viscosity assumed values of $4,16,34,124$, and $435 \mathrm{mPa}$, for SC $4 \%, 8 \%, 10 \%, 12 \%$, and $14 \%$, respectively. Our results were in agreement with Hermansson [25] who suggested that the increase in viscosity with concentration was due to the amount of swollen, not fully solvated, caseinate particles. Khwaldia and colleagues [26] reported that SC solutions exhibited a Newtonian behavior for protein concentrations below 9\%; beyond which a slightly shear thickening behavior was observed. The pseudoplastic behavior can occur in highly solvated dispersed systems. At a low shear rate, the dispersed solute molecules or particles form a solvated layer structure, reducing the mobility of the system. High shear rate can remove the solvated layers, reducing the size of aggregates, allowing a constant apparent viscosity [27].

The dependence of the viscosity on SC concentration has been well described by Equation (2), as shown in Figure 1B. The estimated value of "a" parameter was equal to $1.96 \times 10^{-6}, 1.21 \times 10^{-6}$, and $6.6 \times 10^{-7} \mathrm{mPa} \cdot \mathrm{s}$ at $15,22.5$, and $30^{\circ} \mathrm{C}$, respectively. At higher temperatures it remained constant and equal to the value obtained at $30^{\circ} \mathrm{C}$. The $b$ parameter was constant as a function of temperature and equal to 7.3 for all the temperatures analyzed.

The effect of temperature on solution viscosity was well described by the Arrhenius model (Figure 1C), and the estimated parameters are reported in Table 1. SC concentration affected the values 
of activation energy $(E)$ and $\eta_{0}$ which assumed a higher value at high SC concentration which increased by increasing the SC concentration. This indicates that the effect of the temperature on the decrease in viscosity is more accentuated at higher concentrations of sodium caseinate solutions. These results are in agreement with Barreto et al. [21] who studied the rheological properties of sodium caseinate film forming solutions, in terms of concentration, temperature, and plasticizer content.

\subsection{Kinetics of Water Desorption}

The drying rate of SC at $4 \%, 8 \%, 10 \%, 12 \%$, and $14 \%$ was equal to $0.0063,0.00168,0.00138,0.00107$, and $0.00105 \mathrm{mg}_{\mathrm{H}_{2} \mathrm{O}} \cdot \mathrm{mg}_{\text {solids }}{ }^{-1} \cdot \mathrm{min}^{-1} \cdot \mathrm{m}^{-2}$, respectively. These results indicated that the drying rate is affected by the protein concentration. Indeed, the lower the sodium caseinate concentration, the faster the drying rate. The difference of drying rate could be explained considering that different amounts of proteins affect differently the samples' water activity, which decreases during their dehydration. However, no differences were observed between SC 12\% and SC $14 \%$. All the solution reached equilibrium after about $430 \mathrm{~min}(7 \mathrm{~h})$, except for SC 4\%, which reached equilibrium after $219 \mathrm{~min}$ $(3.6 \mathrm{~h})$. The SC concentration also affected the total amount of water loss; once the equilibrium was reached, the percentage of water loss expressed for gram of solids, was equal to $96 \%, 91 \%, 89 \%, 86 \%$, and $84 \%$ for $4 \%, 8 \%, 10 \%, 12 \%$, and $14 \%$ SC concentrations, respectively. Residual moisture content $(\mathrm{m} \%)$ is reported in Table 2.

Table 2. Surface density $(\rho)$, thickness $(x)$, colorimetric parameters $\left(L^{*}, a^{*}, b^{*}, \Delta E\right)$, residual moisture content $(m)$, water vapor permeability $(W V P)$, and water vapor transmission rate $(W V T R)$ of the SC-based films.

\begin{tabular}{|c|c|c|c|c|c|c|c|c|c|}
\hline Sample & $\begin{array}{c}\rho \\
\left(\mathrm{mg} \cdot \mathrm{cm}^{-2}\right)\end{array}$ & $x(\mu \mathrm{m})$ & $L^{*}$ & $a^{*}$ & $b^{*}$ & $\Delta E$ & $m(\%)$ & $\begin{array}{c}W V P \times 10^{-11} \\
\mathrm{~g} \cdot \mathrm{m}^{-1} \cdot \mathrm{s}^{-1} \cdot \mathrm{Pa}^{-1}\end{array}$ & $\begin{array}{c}\text { WVTR } \\
\mathrm{g} \cdot \mathrm{m}^{-2} \cdot \text { day }^{-1}\end{array}$ \\
\hline SC $4 \%$ & 3.88 & $35 \pm 5^{\mathrm{a}}$ & $96.1 \pm 0.2^{c}$ & $0.10 \pm 0.06^{c}$ & $2.2 \pm 0.5^{\mathrm{a}}$ & $1.0 \pm 0.3^{\mathrm{a}}$ & 10.4 & $6.0 \pm 0.3^{b}$ & $346 \pm 17^{b}$ \\
\hline SC $8 \%$ & 7.76 & $54 \pm 9^{b}$ & $95.3 \pm 0.6^{b}$ & $0.02 \pm 0.13^{\mathrm{b}}$ & $2.2 \pm 0.5^{\mathrm{a}}$ & $1.74 \pm 0.6^{\mathrm{a}}$ & 12.06 & $5 \pm 2^{\mathrm{ab}}$ & $216 \pm 35^{\mathrm{a}}$ \\
\hline SC $12 \%$ & 11.64 & $83 \pm 9^{c}$ & $96.5 \pm 0.3^{c}$ & $-0.10 \pm 0.09^{b}$ & $4.7 \pm 0.4^{\mathrm{b}}$ & $2.9 \pm 0.4^{\mathrm{b}}$ & 12.75 & $4.0 \pm 0.6^{\mathrm{a}}$ & $190 \pm 26^{a}$ \\
\hline SC $14 \%$ & 13.58 & $101 \pm 14^{\mathrm{d}}$ & $92.8 \pm 0.8^{\mathrm{a}}$ & $-1.82 \pm 0.28^{\mathrm{a}}$ & $16.3 \pm 2.3^{c}$ & $15.1 \pm 2.5^{c}$ & 14.1 & $8.00 \pm 0.09^{c}$ & $204 \pm 3^{\mathrm{a}}$ \\
\hline
\end{tabular}

* means within a column with the same lower-case letter are not significantly different $(p>0.05)$.

\subsection{Amount of Coating Adhered on Fennel and Coating Thickness}

Figure 2A shows the average liquid film thickness as function of draining time and viscosity of the biopolymer solution.

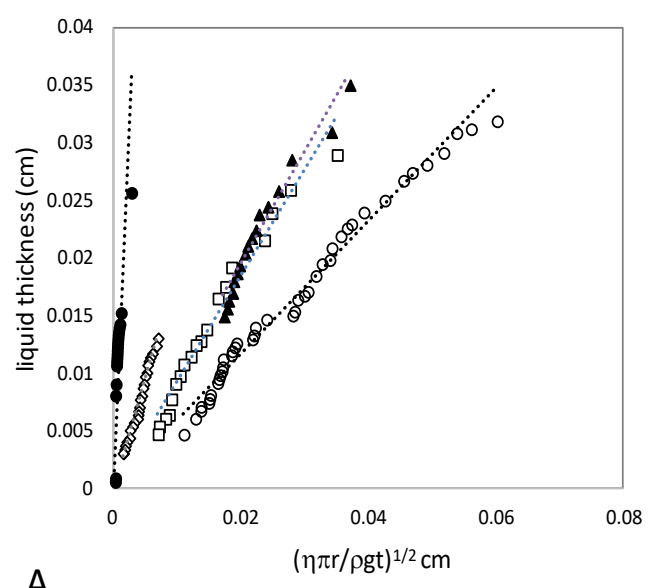

A

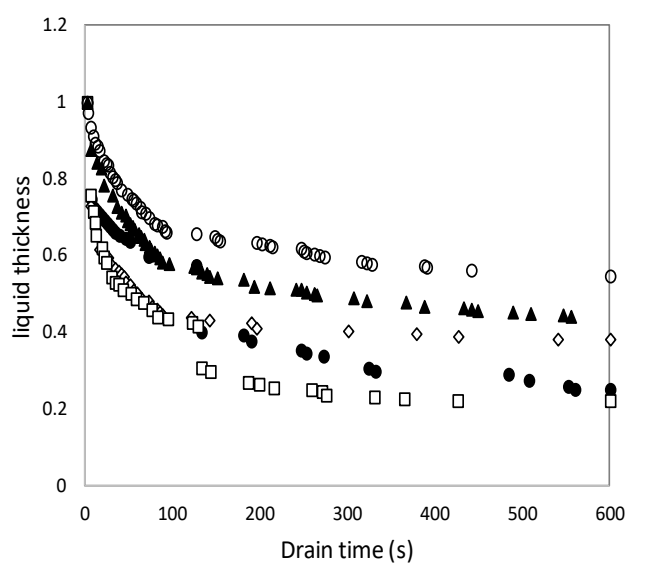

B

Figure 2. Fennel liquid film thickness dependence on viscosity, height curvature, density, and draining time of SC coating solutions at different concentrations (A). Liquid thickness, expressed as ratio between thickness at time $\mathrm{t}$ divided by thickness at time zero, vs. draining time for SC coatings at: $4 \%(\bullet), 8 \%(\diamond)$, $10 \%(\square), 12 \%(\mathbf{A})$, and $14 \%(\bigcirc)(B)$. 
The slope of the function is the dimensionless flow constant $(K)$ as reported by Equation (3) (Table 3).

Table 3. Density of SC solutions $(\rho)$, dimensionless $K$ factor, average liquid film thickness on fennel $\left(h_{\text {avg }}\right)$, density of SC film $\left(\rho_{\mathrm{f}}\right)$, and average dry coating thickness on fennel $\left(H_{\mathrm{avg}}\right)$ as function of $\mathrm{SC}$ concentration.

\begin{tabular}{cccccc}
\hline Sample & $\boldsymbol{\rho}\left(\mathbf{g} \cdot \mathbf{c m}^{-3}\right)$ & $\boldsymbol{K}$ & $\boldsymbol{h}_{\text {avg }}(\boldsymbol{\mu m})$ & $\rho_{f}\left(\mathbf{g} \cdot \mathbf{c m}^{-3}\right)$ & $\boldsymbol{H}_{\text {avg }}(\boldsymbol{\mu m})$ \\
\hline SC $4 \%$ & 0.98 & 13 & 18 & 1.14 & 0.61 \\
SC $8 \%$ & 0.96 & 1.91 & 33 & 1.33 & 1.90 \\
SC $10 \%$ & 0.94 & 0.92 & 36 & 1.35 & 2.52 \\
SC $12 \%$ & 0.93 & 0.97 & 74 & 1.37 & 6.06 \\
SC 14\% & 0.92 & 0.58 & 78 & 1.40 & 7.20 \\
\hline
\end{tabular}

The $K$ constant was affected by SC solutions' concentration and it decreased as the concentration increased. $K$ value has been reported as dependent on the type of solution and surface used [28], whereas Cisneros-Zevallos and Krochta, [8] showed that it was independent by biopolymer solution $(1 \%-4 \%)$ and to assume a constant value of 0.7 for hydroxypropyl methyl cellulose (HPMC) solution. Our results indicated that the average liquid film thickness on coated fennel is a function of viscosity, density of the biopolymer solution, and draining time. Liquid film thickness $\left(h_{\text {avg }}\right)$ decreases as draining time increases and increases with solution viscosity (Figure 2B). After $400 \mathrm{~s}$ draining time, there was no apparent change in the liquid thickness, thus this time $\left(t_{\mathrm{f}}\right)$ was used to estimate the liquid and dry thickness of coating/film on fennel after draining (Table 3). The average liquid thickness on coated fennels estimated changes from 18 to $78 \mu \mathrm{m}$ increasing the SC concentration from $4 \%$ to $14 \%$. The respectively dry film thickness ranged from 0.62 to $7.2 \mu \mathrm{m}$. This dependence is justified by viscosity dependence by the solid concentration (Equation (2)). Coating thickness was reported to be in the range of 0.08 to $2.1 \mu \mathrm{m}$ for HPMC solution [8] and 4.5 to $13 \mu \mathrm{m}$ for semperfresh ${ }^{\mathrm{TM}}$ sucrose $^{2}$ polyester solution [7].

\subsection{Physiochemical Properties and WVP}

The solid surface density and the thickness of the film are reported in Table 2. Our results showed that, by increasing the SC concentration, both the solid surface density and the film thickness increased. For the thickness there were significant differences between different concentrations of SC $(p<0.05)$. Lower thickness values were reported by Schou et al. [29] and Longares and co-workers [30]; the differences with our results could be due to the higher Gly/SC they used at 0.16 and 0.32 , respectively.

The sodium caseinate film appeared homogeneous and transparent, but as the concentration of SC increased, the whitish color of the film increased. The color parameters are summarized in Table 2: $\Delta E$ is a global indicator of color changes and it varied from $1.03 \pm 0.31$ for SC $4 \%$ to $15.12 \pm 2.47$ for the sample with SC $14 \%$; this last sample showed significantly higher $\Delta E$ compared to the other samples $(p<0.05)$. This parameter was found to be lower than those reported by Volpe and colleagues [20]; since they investigated chitosan-sodium caseinate blend films at different concentrations, the different value $\Delta E$ was due to the presence of chitosan in their films.

Film moisture content was in the range of $10 \%$ to $14.1 \%$ for SC solution from $4 \%$ to $14 \%$. Similar results were reported by Schou et al. [29] for about 10 (g water/100 $\mathrm{g}$ film), even though they used more diluted SC solutions.

The water vapor transmission rate (WVTR) and water vapor permeability $(W V P)$ values are reported in Table 2. As general trend the WVTR decreased as the concentration of SC increased, although there were no significant differences among the samples, except for SC $4 \%$ which had a statistically different value $\left(346 \pm 17 \mathrm{~g} \cdot \mathrm{m}^{-2} \cdot \mathrm{day}^{-1}\right)(p<0.05)$. Poor water vapor barrier of films is related to their hydrophilic nature, which lets water vapor molecules dissolve and pass through the film matrix [31]. 
Our results are similar to those reported by Brzoska and co-workers [32], who studied films made with a $10 \%$ SC solution, with a Gly/SC ratio of 0.66 . They reported a WVTR of $200 \mathrm{~g} \mathrm{~m}^{-2}$ day $^{-1}$ at $20^{\circ} \mathrm{C}$ and $50 \%$ RH.

Comparing the films in terms of permeability, film at $8 \%, 10 \%$, and $12 \%$ showed comparable value of about $5 \times 10^{-11} \mathrm{~g} \cdot \mathrm{m}^{-1} \cdot \mathrm{s}^{-1} \cdot \mathrm{Pa}^{-1}$, whereas film at $4 \%$ and $14 \%$ showed the highest WVP values $(p<0.05)$. However, our results of WVP were in the same order of magnitude as that reported in previous studies $[3,31,33]$.

\subsection{Antioxidant Activity}

The $\mathrm{IC}_{50}$ of GA and REO is $23.9 \mu \mathrm{g} / \mathrm{mL}$ and $14.7 \mathrm{mg} / \mathrm{mL}$, respectively. The geographical origin has been shown to affect the antioxidant capacity of REO which assumed a value in the range of $16.45 \mathrm{mg} / \mathrm{mL}$ to $23.8 \mathrm{mg} / \mathrm{mL}$ if was from China or the Mediterranean region. The GA IC 50 value determined in this work was slightly lower than the one reported by Khan and colleagues [34] who found that the $\mathrm{IC}_{50}$ of gallic acid was equal to $19.0 \mu \mathrm{g} / \mathrm{mL}$. The DPPH radical scavenging capacity of SC solution with GA (SC/GA) and REO (SC/REO) is shown in Figure 3.

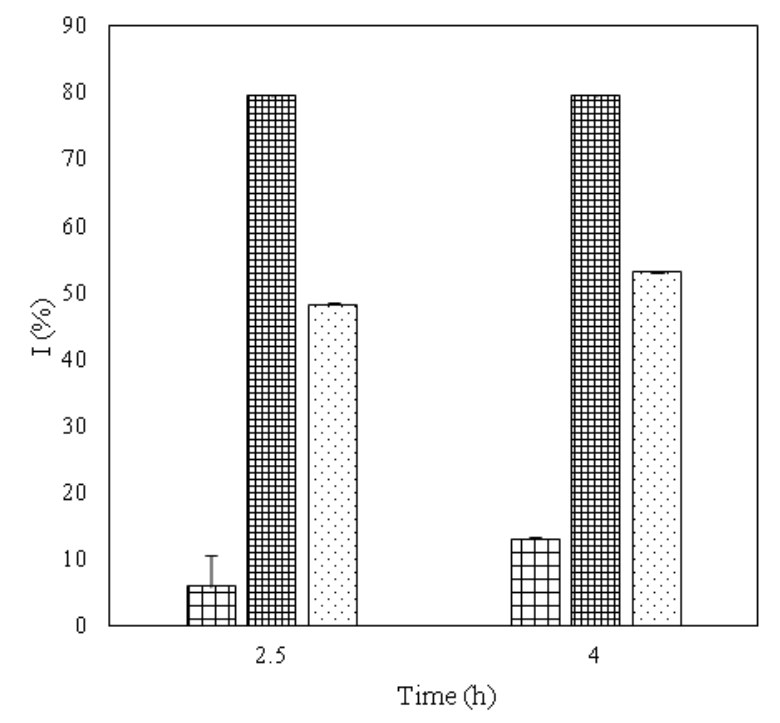

Figure 3. Antioxidant activity, inhibition (\%) of film forming solutionof sodium caseinate (囲),

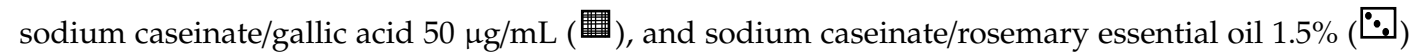
$(w / v)$, after 2.5 and $4 \mathrm{~h}$ of contact with DPPH radicals at room temperature.

Generally, the antioxidant activities increased by the addition of gallic acid and rosemary essential oil. The lowest inhibition (I\%) was detected for SC, which assume a value of $5.9 \% \pm 1.5 \%$, after $2.5 \mathrm{~h}$ and $13 \% \pm 0.3 \%$, after $4 \mathrm{~h}$. When GA was added to the SC solution, $I \%$ reached a value of $79.3 \% \pm 0.4 \%$, after $2.5 \mathrm{~h}$, and then remained constant. In the case of SC/REO, the I\% increased to $48.1 \% \pm 0.3 \%$, after $2.5 \mathrm{~h}$ and up to $52.9 \% \pm 0.2 \%$, after $4 \mathrm{~h}$.

Comparing the $\mathrm{IC}_{50}$ value of $\mathrm{REO}$ and I\% of SC/REO, the results showed that SC/REO have an antioxidant activity close to the activity of pure REO at the same concentration. In fact, we used a quantity of REO in the film to get a $50 \%$ of $\mathrm{I} \%$ and by including the REO in the CS, the antioxidant activity was confirmed. This result suggests that all the H+ of the REO were donated to the DPPH radicals after $4 \mathrm{~h}$. For GA, the antioxidant activity measured when GA was included in SC is lower than the theoretical one expected. In fact, the quantity of GA used was the double of the $\mathrm{IC}_{50}$ value, thus a 100\% DPPH inhibition was expected. The lower antioxidant capacity measured when the active compound is dispersed in SC coating can be justified by the interaction between SC and GA that reduces the available active site of GA $[35,36]$. 


\section{Conclusions}

Sodium caseinate solutions followed a Newtonian behavior and the dependence of the viscosity by solids concentration was well described by a power law. Hence, the dependence of viscosity by temperature was well described by an Arrhenius-type equation and both activation energy $(E)$ and $\eta_{0}$ increased by increasing the SC concentration. Physical principles applied to dip-plate coating were applied to food coating system. Results highlighted that viscosity affected the liquid and dry coating thickness which ranged between 20 and 70 and 0.7 and $6.4 \mu \mathrm{m}$, respectively, for SC samples between $4 \%$ and $14 \%$. Thus, to compare coating performance or to choose the optimal coating composition is not appropriate to consider only the solid concentration, but rheological properties of solution must be known. The solid concentration affects the drying rate too. It was found to be in the range of 0.0063-0.00107 $\mathrm{mg}_{\mathrm{H}_{2} \mathrm{O}} \cdot \mathrm{mg}_{\text {solids }}{ }^{-1} \cdot \mathrm{min}^{-1} \cdot \mathrm{m}^{-2}$ by increasing the SC concentration. Results on antioxidant activity of the bioactive coating were very good, highlighting that sodium caseinate can be a good substrate for dispersion active compounds, mainly for rosemary essential oil, for the developing of bioactive coating. More investigations are needed to validate the results obtained in terms of coating thickness and to evaluate the efficacy of the coating for preserving food quality.

Author Contributions: Conceptualization, S.C. and E.T.; data curation, M.V., S.V., and F.A.D.G.; formal analysis, M.V., S.V., and F.A.D.G.; methodology, E.T.; supervision, S.C. and E.T.; writing-original draft, M.V., S.V., and E.T.; writing-review \& editing, S.C. and E.T. All authors have read and agreed to the published version of the manuscript.

Funding: The authors gratefully thank European Union's H2020 research and Innovation Programme (No. 817936). The PhD fellowship of Fabio Angelo Di Giuseppe was supported by the Ministry of Education University and Research (MIUR) in the frame of the National Operational Program ESF-ERDF Research and Innovation 2014-2020, action I.1. Innovative $\mathrm{PhD}$ with industrial characterization.

Acknowledgments: We acknowledge Commerciale Export (Pagani, Italy) for supplying the fennels employed in this work.

Conflicts of Interest: The authors declare no conflicts of interest.

\section{References}

1. Yousuf, B.; Qadri, O.S.; Srivastava, A.K. Recent developments in shelf-life extension of fresh-cut fruits and vegetables by application of different edible coatings: A review. LWT 2018, 89, 198-209. [CrossRef]

2. Volpe, S.; Cavella, S.; Torrieri, E. Biopolymer coatings as alternative to modified atmosphere packaging for shelf life extension of minimally processed apples. Coatings 2019, 9, 569. [CrossRef]

3. Colak, B.Y.; Gouanve, F.; Degraeve, P.; Espuche, E.; Prochazka, F. Study of the influences of film processing conditions and glycerol amount on the water sorption and gas barrier properties of novel sodium caseinate films. J. Membr. Sci. 2015, 478, 1-11. [CrossRef]

4. Hernandez-Izquierdo, V.M.; Krochta, J.M. Thermoplastic processing of proteins for film formation-A review. J. Food Sci. 2008, 73, R30-R39. [CrossRef] [PubMed]

5. Certel, M.; Uslu, M.K.; Ozdemir, F. Effects of sodium caseinate- and milk protein concentrate-based edible coatings on the postharvest quality of Bing cherries. J. Sci. Food Agric. 2004, 84, 1229-1234. [CrossRef]

6. Iahtisham-Ul-Haq; Butt, M.S.; Suleria, H.A.R.; Ahmed, W. Physicochemical behavior of zinc-fortified, sodium caseinate-based, edible-coated apricots during storage in controlled atmosphere: Zinc-fortified edible coating of apricots. J. Food Process. Preserv. 2015, 39, 2431-2441. [CrossRef]

7. Park, H.; Bunn, J.; Vergano, P.; Testin, R. Gas permeation and thickness of the sucrose polyester Semperfresh coatings on apples. J. Food Proc. Preserv. 1994, 8, 349-358. [CrossRef]

8. Cisneros-Zevallos, L.; Krochta, J.M. Dependence of coating thickness on viscosity of coating solution applied to fruits and vegetables by dipping method. J. Food Sci. 2003, 68, 503-510. [CrossRef]

9. Carocho, M.; Barreiro, M.F.; Morales, P.; Ferreira, I.C.F.R. Adding molecules to food, pros and cons: A review on synthetic and natural food additives. Compr. Rev. Food Sci. Food Saf. 2014, 13, 377-399. [CrossRef]

10. Bonilla, J.; Sobral, P.J.A. Antioxidant and physicochemical properties of blended films based on gelatin-sodium caseinate activated with natural extracts. J. Appl. Polym. Sci. 2017, 134. [CrossRef]

11. Strlič, M.; Radovič, T.; Kolar, J.; Pihlar, B. Anti- and prooxidative properties of gallic acid in fenton-type systems. J. Agric. Food Chem. 2002, 50, 6313-6317. [CrossRef] [PubMed] 
12. Kivilompolo, M.; Obůrka, V.; Hyötyläinen, T. Comparison of GC-MS and LC-MS methods for the analysis of antioxidant phenolic acids in herbs. Anal. Bioanal. Chem. 2007, 388, 881-887. [CrossRef] [PubMed]

13. Shan, B.; Cai, Y.Z.; Sun, M.; Corke, H. Antioxidant capacity of 26 spice extracts and characterization of their phenolic constituents. J. Agric. Food Chem. 2005, 53, 7749-7759. [CrossRef] [PubMed]

14. De Vasconcelos, M.D.C.B.M.; Bennett, R.N.; Rosa, E.A.S.; Cardoso, J.V.F. Primary and secondary metabolite composition of kernels from three cultivars of portuguese chestnut (castanea sativa mill.) at different stages of industrial transformation. J. Agric. Food Chem. 2007, 55, 3508-3516. [CrossRef]

15. Kahraman, T.; Issa, G.; Bingol, E.B.; Kahraman, B.B.; Dumen, E. Effect of rosemary essential oil and modified-atmosphere packaging (MAP) on meat quality and survival of pathogens in poultry fillets. Braz. J. Microbiol. 2015, 46, 591-599. [CrossRef]

16. Pereira, P.S.; Maia, A.J.; Tintino, S.R.; Oliveira-Tintino, C.D.D.M.; Raulino, I.S.D.S.; Vega, M.C.; Rolón, M.; Coronel, C.; Barros, L.M.; Duarte, A.E.; et al. Trypanocide, antileishmania and cytotoxic activities of the essential oil from Rosmarinus officinalis L in vitro. Ind. Crops Prod. 2017, 109, 724-729. [CrossRef]

17. Qiu, X.; Jacobsen, C.; Sørensen, A.-D.M. The effect of rosemary (Rosmarinus officinalis L.) extract on the oxidative stability of lipids in cow and soy milk enriched with fish oil. Food Chem. 2018, 263, 119-126. [CrossRef]

18. Wang, B.; Ma, L.; Yin, L.; Chen, J.; Zhang, Y.; Dong, L.; Zhang, X.; Fu, X. Regional variation in the chemical composition and antioxidant activity of Rosmarinus officinalis L. from China and the Mediterranean region. Pak. J. Pharm. Sci. 2018, 31, 221-229.

19. Moreno, S.; Scheyer, T.; Romano, C.S.; Vojnov, A.A. Antioxidant and antimicrobial activities of rosemary extracts linked to their polyphenol composition. Free Radic. Res. 2006, 40, 223-231. [CrossRef]

20. Volpe, S.; Cavella, S.; Masi, P.; Torrieri, E. Effect of solid concentration on structure and properties of chitosan-caseinate blend films. Food Packag. Shelf Life 2017, 13, 76-84. [CrossRef]

21. Barreto, P.L.M.; Roeder, J.; Crespo, J.S.; Maciel, G.R.; Terenzi, H.; Pires, A.T.N.; Soldi, V. Effect of concentration, temperature and plasticizer content on rheological properties of sodium caseinate and sodium caseinate/sorbitol solutions and glass transition of their films. Food Chem. 2003, 82, 425-431. [CrossRef]

22. ASTM. Standard Test Methods for Water-Vapor Transmission Of Materials E96-93; ASTM: West Conshohocken, PA, USA, 1993; Volume 04.06, pp. 701-708.

23. Gülçin, İ.; Huyut, Z.; Elmastaş, M.; Aboul-Enein, H.Y. Radical scavenging and antioxidant activity of tannic acid. Arab. J. Chem. 2010, 3, 43-53. [CrossRef]

24. Hromis, N.; Lazic, V.; Markov, S.; Vastag, Z.; Popovic, S.; Suput, D.; Dzinic, N. Improvement of antioxidant and antimicrobial activity of chitosan film with caraway and oregano essential oils. Acta Per. Tech. 2014, 33-43. [CrossRef]

25. Hermansson, A.-M. Functional properties of proteins for foods-flow properties. J. Texture Stud. 1975, 5, 425-439. [CrossRef]

26. Khwaldia, K.; Banon, S.; Perez, C.; Desobry, S. Properties of sodium caseinate film-forming dispersions and films. J. Dairy Sci. 2004, 87, 2011-2016. [CrossRef]

27. Carr, A. Rheology of Sodium Caseinate Solutions. Master's Thesis, Massey University, Palmerston North, New Zaeland, 1994.

28. Guglielmi, M.; Colombo, P.; Peron, F.; Mancinelli Degli Esposti, L. Dependence of thickness on the withdrawal speed for $\mathrm{SiO}_{2}$ and $\mathrm{TiO}_{2}$ coatings obtained by the dipping method. J. Mater Sci. 1992, 27, 5052-5056. [CrossRef]

29. Schou, M.; Longares, A.; Montesinos-Herrero, C.; Monahan, F.J.; O’Riordan, D.; O'Sullivan, M. Properties of edible sodium caseinate films and their application as food wrapping. LWT-Food Sci. Technol. 2005, 38, 605-610. [CrossRef]

30. Longares, A.; Monahan, F.J.; O'Riordan, E.D.; O'Sullivan, M. Physical properties of edible films made from mixtures of sodium caseinate and WPI. Int. Dairy J. 2005, 15, 1255-1260. [CrossRef]

31. Moghaddas Kia, E.; Ghasempour, Z.; Alizadeh, M. Fabrication of an eco-friendly antioxidant biocomposite: Zedo gum/sodium caseinate film by incorporating microalgae (Spirulina platensis): ARTICLE. J. Appl. Polym. Sci. 2018, 135, 46024. [CrossRef]

32. Brzoska, N.; Müller, M.; Nasui, L.; Schmid, M. Effects of film constituents on packaging-relevant properties of sodium caseinate-based emulsion films. Prog. Org. Coat. 2018, 114, 250-258. [CrossRef] 
33. Alizadeh-Sani, M.; Rhim, J.-W.; Azizi-Lalabadi, M.; Hemmati-Dinarvand, M.; Ehsani, A. Preparation and characterization of functional sodium caseinate/guar gum/ $\mathrm{TiO}_{2} /$ cumin essential oil composite film. Int. J. Biol. Macromol. 2020, 145, 835-844. [CrossRef] [PubMed]

34. Khan, R.A.; Khan, M.R.; Khan, A. Comparative antioxidant scavenging and lipid peroxidation activity of rutin and gallic acid. Bangladesh J. Pharmacol. 2015, 10, 637. [CrossRef]

35. Yildirim-Elikoglu, S.; Erdem, Y.K.A. Interactions between milk proteins and polyphenols: Binding mechanisms, related changes and the future trends in dairy industry. Food Rev. Int. 2017, 34, 665-697. [CrossRef]

36. Helal, A.; Tagliazucchi, D.; Conte, A.; Desobry, S. Antioxidant properties of polyphenols incorporated in casein/sodium caseinate films. Int. Dairy J. 2012, 25, 10-15. [CrossRef]

C 2020 by the authors. Licensee MDPI, Basel, Switzerland. This article is an open access article distributed under the terms and conditions of the Creative Commons Attribution (CC BY) license (http://creativecommons.org/licenses/by/4.0/). 